\title{
Research on Socialized Development Path of College Physical Education
}

\author{
Linyi Wang ${ }^{1}$, Qiao'e Yu ${ }^{2}$ \\ ${ }^{1}$ Applied Technology College of Dalian Ocean University, No.2, China \\ ${ }^{2}$ Applied Technology College of Dalian Ocean University, No.2, China
}

Keywords: College physical education; socialized; college students

\begin{abstract}
Socialized development of college physical education is the result of full development of social sports and people's increasing enthusiasm for sports. Abundant sports facilities, professional talents and sports events source give full support of college physical education, colleges students' interesting learning, extensive learning and individualized learning, also push the development of sports culture and sports project, and also make the preparations in regard to knowledge, skills, sports culture atmosphere and education talents.
\end{abstract}

\section{Introduction}

In the opportunities of reform in colleges education, the development of physical education with the path of socialization is an important way for the campus sports culture to be rich and social sports resources to explore and innovate. In particular, on the basis of the physical education teaching system and subject settings set forth in colleges and universities, national folk sports programs, specific social sports programs or skills, and social fashion sports programs are taught as optional courses and featured courses. Introducing outstanding folk technique inheritors, people with sports talent, retired athletes to schools, improving the structure of school teachers, and scientifically developing or directly using sports enterprises' work place or urban public sports venues could effectively achieve the comprehensive effects of talents, hardware, and curriculum development for the socialization of college sports teaching.

\section{The Path of the Socialized Development of College Physical Education}

The realization of colleges socialized physical education is one of the results of scientific development of socialized sports resources and sports talents in accordance with the laws of colleges physical education. There are mainly three ways to achieve the socialization development of physical education in colleges.

\subsection{Co-construction by colleges and enterprises}

The joint construction of colleges and sports enterprises is one of the common paths for the socialized development of physical education in colleges. According to the different nature of the enterprises, there are three development paths as follow:

\subsubsection{Co-construction with sports apparel companies}

In view of the protection role of sports apparel products for sporters, this type of teaching focuses on apparel and its health care functions. As for college students who specialize in apparel design, it can design teaching model which is beneficial to personal professional development. In the operation of teaching socialization, it is possible to introduce enterprise design personnel into colleges and college students into enterprises.

\subsubsection{Co-construction with sports equipment companies}

Sports equipment is the basic hardware for sports learning and sports-launching. Jointly constructing with such enterprises can educate college students from the perspectives of research, development and production. For example, how to conduct body building scientifically, how to 
innovate individual skills and how to invent equipment according to individual needs.

\subsubsection{Co-construction with fitness companies (clubs)}

This is a comprehensive construction of venues, equipment, and coaches with various fitness clubs, venues, and halls as its foundation. It is the most socialized development model with the best maneuverability and results.

\subsection{Application of off-campus facilities}

With the vigorous development of mass sports, various kinds of public sports facilities have also been increasingly built. In view of the reality of the decline in the physical fitness of college students, using fitness facilities in society in an appropriate way is an effective way to cultivate students' interest in sports and increase their physical activity. There are two ways to start teaching:

\subsubsection{Application of community-based public facilities}

With a variety of outdoor facilities, including spacewalkers, supine boards, seated trainers and rowing machines, teachers can educate students to use such equipment or facilities scientifically to develop targeted sports training and teaching according to the different conditions of their physical fitness.

\subsubsection{Application of professional public stadiums in cities}

It mainly refers to the city's large stadiums. Colleges sports teachers can choose the appropriate timing and projects to lead students to such venues to carry out professional teaching activities in the form of friendship competition or special teaching methods according to the needs of education. It meet both the complementary needs of sports facilities in the colleges and public sports venues in the city and the professional atmosphere requirements for specific projects.

\subsection{Social project elective course settings}

Within the framework of relevant laws and regulations and education systems, the selective introduction of social projects is an effective vehicle for enriching the physical education curriculum system. There are two kinds of operational settings:

\subsubsection{Elective course settings}

That is to say, a project that is mature and is relatively complete in the system is selected as the elective course for the undergraduates after the arrangement, processing, and technicalization of sport education and teaching. For example, martial arts elective courses in various disciplines can be carried out within a certain period of time due to its need for systematic basic skills training, single skills training, etc. It is one of the most typical paths for the socialized development of college physical education.

\subsubsection{Single-choice and single-skill settings}

Colleges sports teachers or management departments could mainly focus on short and easy-to-learn teaching activities for students with short time and little content. Because of the skills are simple and the procedures are few, several lessons or even one lesson can be taken to complete the teaching, so that students can master basic skills and carry out personalized activities, such as gyro and other projects in a short time.

\section{The Operating Mode of Socialized Development of College Physical Education}

In the process of the socialization of physical education in colleges, it is necessary to carry out socialized teaching in an appropriate and flexible way, which is an important guarantee for ensuring the orderly, planned and effective socialization of physical education in colleges.

\subsection{Introduction of social sports professionals}

The direct introduction of professional talents from society is one of the economic and efficient 
methods of socialized physical education. There are three ways in the process of implementation:

\subsubsection{Introduce professional athletes}

Professional athletes of various projects and levels are among the best candidates for professional project teaching. They have both professional knowledge, technical skills, and practical experience by participating in various competitions. The introduction of such social personnel as professional teachers are a good way to stimulate college students' interest and learning motivation in sports. For example, under the situation of the vigorous development of campus football, a national football player can be hired as a professional football teacher.

\subsubsection{Introduce inheritors of traditional ethnic sports}

These inheritors, as the successors or even the only one who mastered a certain ethnic sports project, could go into the campus and carry out teaching in representative projects by following their own knowledge system and personal wishes. Thus, their innovative research and basic knowledge and skill are imparted to students in order to realize the project carrying and culture promoting.

\subsubsection{Introduce all types of fitness professionals}

Allowing a variety of fitness, bodybuilding, square dance, yoga, parkour and other general social activities enthusiasts or person with a specialty to carry out teaching activities within the scope of their abilities to build a more colorful campus sports culture.

\subsection{Social outsourcing teaching of curriculum projects}

In the existing system of colleges and universities, the schools are at a weaker or lower level than the society in the status of teachers, hardware, and scientific research level in colleges. Relevant courses or sports programs being outsourced to a company or individual is social teaching model that is worth trying. From the social outsourcing of projects, there are three forms:

\subsubsection{Outsourcing with compensation}

This means that the school outsources the teaching of a project to a certain organization or individual in a paid manner. The school pays compensation, and the organization or individual pays labor and intelligence.

\subsubsection{Public welfare outsourcing}

This refers to the purely non-profit teaching activities conducted by social institutions and individuals. It employs some well-known people or people with professional skills to teach students free of charge. For example, square dance lovers go to school to teach students to dance square dances.

\subsubsection{On-site teaching and distance learning}

The former refers to face-to-face teaching on and off campus, and the latter refers to remote teaching activities that are carried out through the use of internet and exquisite course resources. Of course, in the actual operation, the school still needs to strengthen the supervision of teaching content, teaching forms, teaching staff quality, and teaching effectiveness in accordance with the relevant laws and regulations to ensure the ideological content, pragmaticality and controllability of teaching.

\subsection{Research-based teaching cooperated by schools and society}

Research-based teaching is one of the important paths for promoting sports innovation and enriching sports culture. It is a teaching style that requires high for schools, students, and social teaching personnel. According to the needs of the teaching content, there are three forms: 


\subsubsection{Research-based teaching in technical skills}

In accordance with the scope of the social teaching staff's expertise, let them integrate the research into the teaching process according to the actual progress of their own research to achieve the unity of teaching and research. The research on the improvement of defects and mistakes in daily sports and training should be made to realize the project and its relevant technical skills more perfect and scientific.

\subsubsection{Research-based teaching in project excavation}

It mainly focuses on various ethnic and traditional sports projects. From the perspective of protecting intangible cultural heritage, it conducts research on project origins, project technologies, project skills, project functions, project cultural connotations and project equipment, aiming to make it be preserved and inherited more systematically and comprehensively and improve the diversity of physical education programs. The conduct of such teaching are mainly depends on the inheritors of various projects and social activists.

\subsubsection{Research-based teaching in function and carrier innovation}

It includes two aspects: First, new function discovery or additional research on the basis of original functions which aims to expand the scope of application of a certain project or its skill to meet the more diverse sports needs of college students; Second, researches on sports forms, sports procedures, sports equipment, equipment production, equipment application arts and especially on new, environmental and safety equipment with the support of modern science and technology. Through this kind of teaching, not only the level and progress of the socialized teaching staff's own research have been enhanced, but also a wealth of information the university's own sports teaching research has accumulated.

\section{Research on Performance Appraisal of Socialized Development of College Physical Education}

Strengthening assessment is an external guarantee to supervise and guide college students to study hard and socialized teaching staff to teach earnestly and innovatively. It is an important way to sum up experience and improve teaching.

\subsection{Knowledge and skill examination}

In combination with the existing examination methods in the teaching of physical education in colleges, there are three types of examinations that are worth referring:

\subsubsection{Theoretical examination}

paper questions, network questions, on-site questions, related writing essays and other examination form that the college students can accurately describe the basic principles, technical skills and their development history.

\subsubsection{Skill examination}

The actual activities are used to demonstrate the skills of the undergraduates in mastering the skills, including the use of group coordination skills, the display of single-person skills and the display of single-person project. Basic elements such as the accuracy of the movement, movement range, movement strength, the beauty of movement and the complete set of movements should be focused on to assess the mastery degree of students’ practical ability and applying ability.

\subsubsection{Social practice examination}

This is a form of examination that allows university students to go to a specific social environment through sports skills dissemination, skills use, and in particular through competitions to test the technical skills of college students such as sports basic skills. For example, students could take part into performances for public welfare. 


\subsection{Physical health assessment}

In accordance with the standards for physical health of college students promulgated by the State, after a certain period of time for carrying out specific socialized teaching, under the support of various existing instruments, regular health assessments should be carried out for college students. There are two general ways:

\subsubsection{Instrument detection}

With a variety of measuring instruments to detect indicators of college students after exercise, for example, heartbeat, pulse, vital capacity, blood pressure and blood sugar, their pre- and post-exercise situation could be accurately measured in order to provide good guidance in teaching and taking exercise for the next step.

\subsubsection{Special sports assessment}

Examining the college students' speed, explosive power, endurance, flexibility and artistry in the exercise of relevant skills or projects to actually test their physical fitness and overall body quality.

\subsection{Sports ability assessment}

As one of their basic qualities, college students' sports ability is the basic ability to support their professional knowledge learning, sports learning and continuous optimization of physical health. According to the development of socialized teaching, three types of capabilities need to be assessed:

\subsubsection{Sports learning awareness}

This refers to the ability to develop specific skills based on the individual's personal health needs and interests. There are theoretical studies, technical skills studies, and complete project studies that could lay a solid foundation in basic sports knowledge and skills.

\subsubsection{Sports communication ability}

It refers to the ability to educate, mobilize, and influence people around based on personal knowledge and skills, including dissemination ability, cultural communication ability, and equipment making ability and so on, which could realize the scientific inheritance of socialized sports contents.

\subsubsection{Sports innovation ability}

In practice, skills innovation, project innovation, equipment innovation, and functional innovation are the main aspects, which will further promote the development of more colorful social sports and provide education for the future health of college students, including entertainment education, fitness education, art education, and interest development education.

\section{Conclusion}

The socialized development of physical education in colleges is one of the important paths for the development of physical science, college physical education and social sports. On the basis of excavating, organizing, and innovating social sports programs and their skills, it not only improves the overall quality of college students, which has laid a good and solid foundation for their future work with more sharing of high-quality social sports resources, but also created more inheritance opportunities for the development of precious national traditional sports, and enrich and innovate the sports culture with the help of college talents.

\section{References}

[1] Z.C. Ji, Z.G. Yao: Journal of Chengdu Sport University, Vol.3(2005) No.3, p101-104. (In Chinese)

[2] S.W. Li: Sports Culture Guide, Vol.4(2007) No.6, p86-87. (In Chinese) 
[3] X.J. Xin: Sports Culture Guide, Vol.4(2006) No.10, p62-64. (In Chinese)

[4] N.X. Ma: Journal of Xi'an Institute of Physical Education, Vol.22(2005) No.4, p832-35. (In Chinese)

[5] X.J. Xin: Journal of Zaozhuang Teachers' College, Vol.20(1996) No.2, p101-103. (In Chinese)

[6] Y. Zhou, P. Shen: Journal of Wuhan Institute of Physical Education, Vol.36(2002) No.2, p32-33. (In Chinese) 